\title{
Fluorescence Quenching of Single Walled Carbon Nanotubes in SDBS Surfactant Suspension by Metal Ions: Quenching Efficiency as a Function of Metal and Nanotube Identity
}

\author{
Jonathan J. Brege, Clayton Gallaway, and Andrew R. Barron* \\ Richard E. Smalley Institute for Nanoscale Science and Technology, Carbon Nanotube \\ Laboratory, and Department of Chemistry, Rice University, Houston, TX 77005
}

Supplementary Materials 


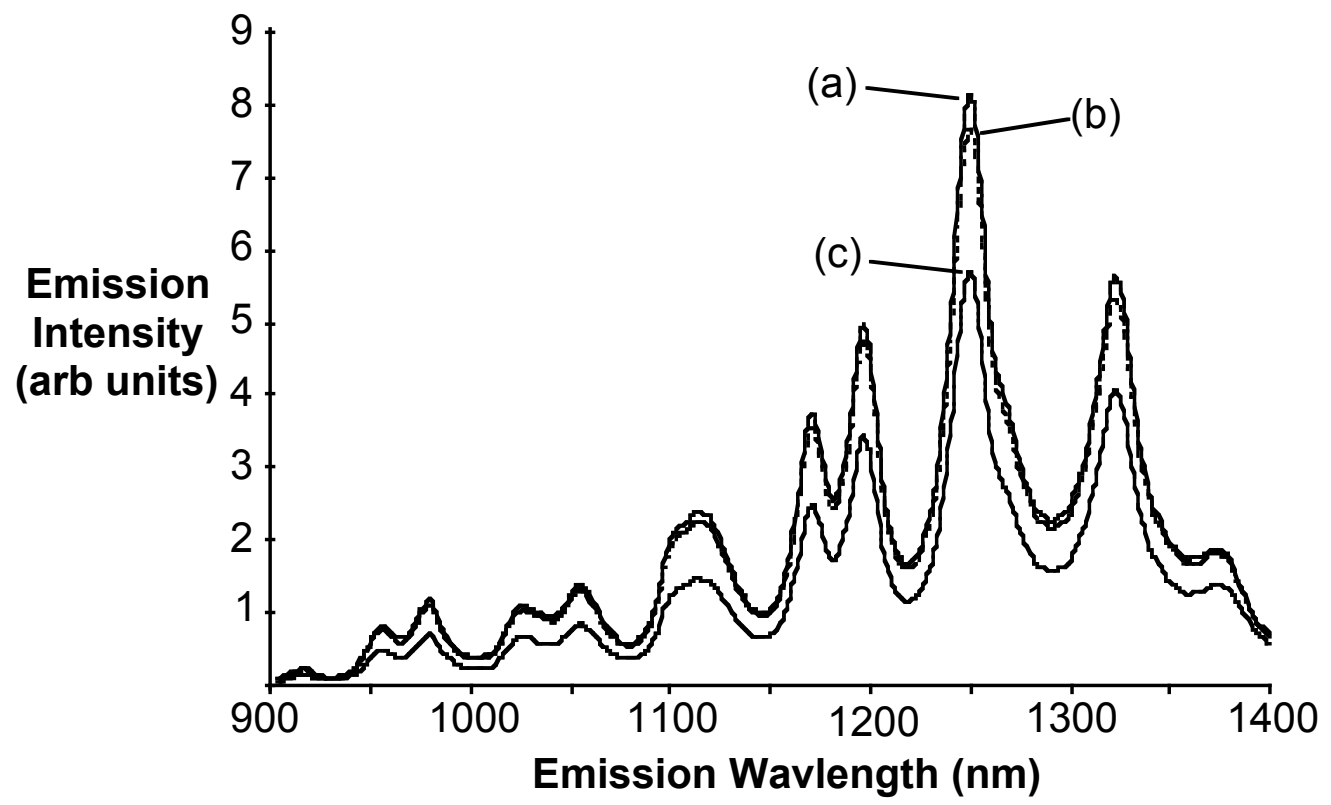

Figure S1. Fluorescence of SDBS-SWNTs using $785 \mathrm{~nm}$ excitation in the presence of $\mathrm{SrCl}_{2}(3.0$ $\mathrm{mM}$ ) before (a) and after (b) the addition of EDTA (15 mM) showing the recovery of fluorescence with the addition of EDTA. The fluorescence spectrum in the presence of EDTA $(15 \mathrm{mM})$ is shown for comparison (c). 
Fluorescence Analysis (785 $\mathrm{nm}$ excitation)

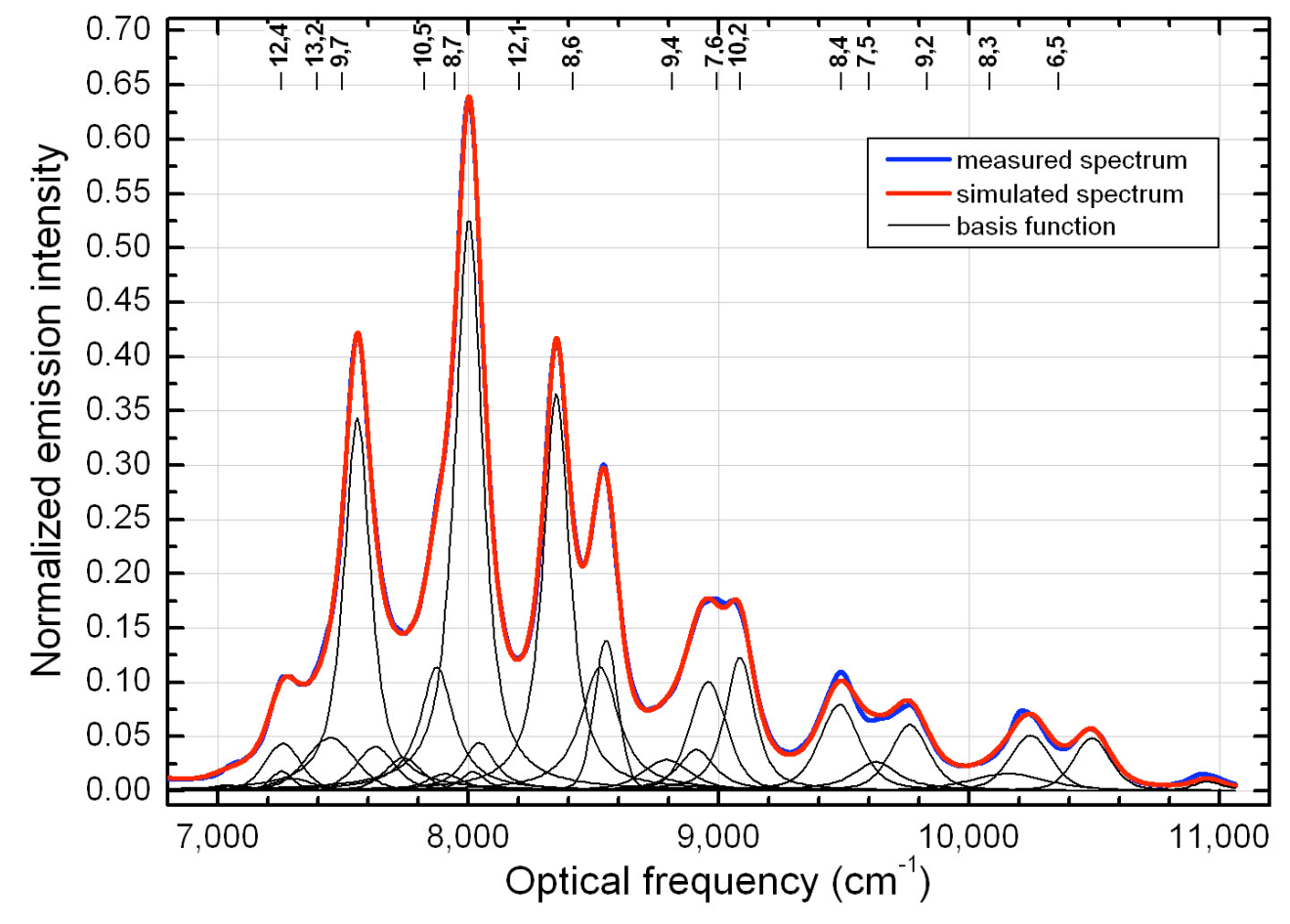

Figure S2. Deconvoluted fluorescence spectra (785 nm excitation) of SDBS-SWNTs. 


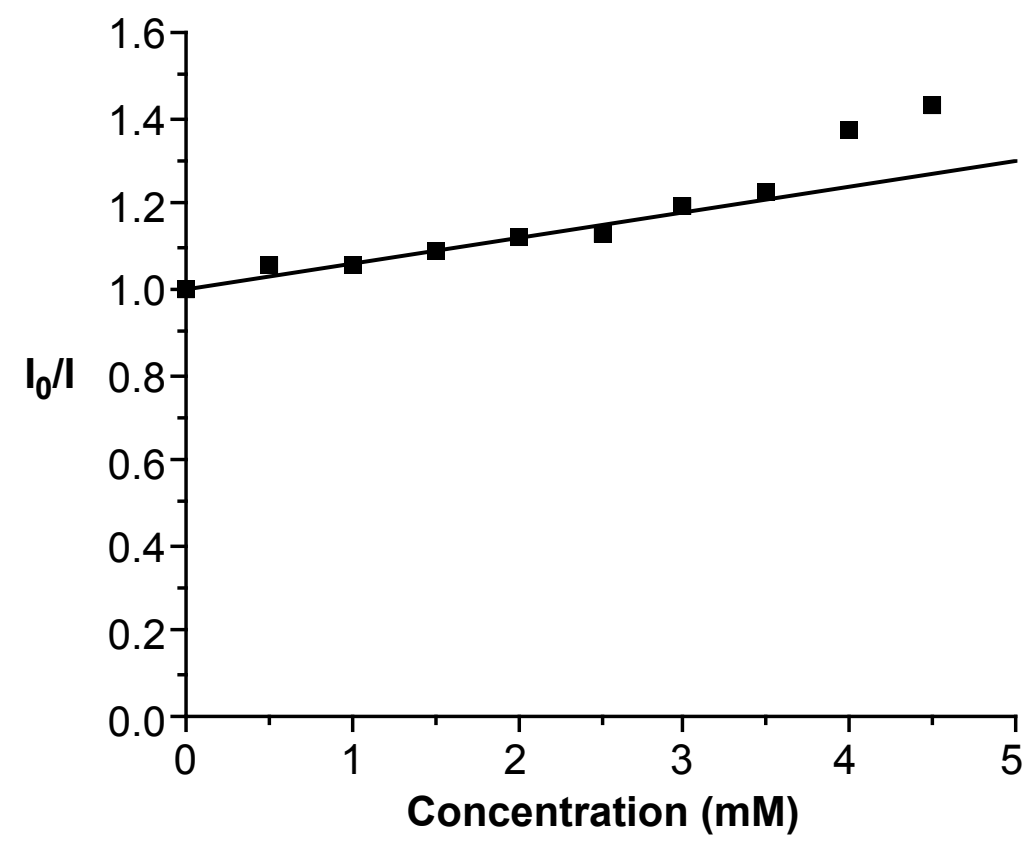

Figure S3. A representative Stern-Volmer plot for quenching of 6,5 SDBS-SWNT by $\mathrm{Hg}(\mathrm{OAc})_{2}$ measured using $785 \mathrm{~nm}$ excitation $\left(\mathrm{R}^{2}=0.968\right)$. 


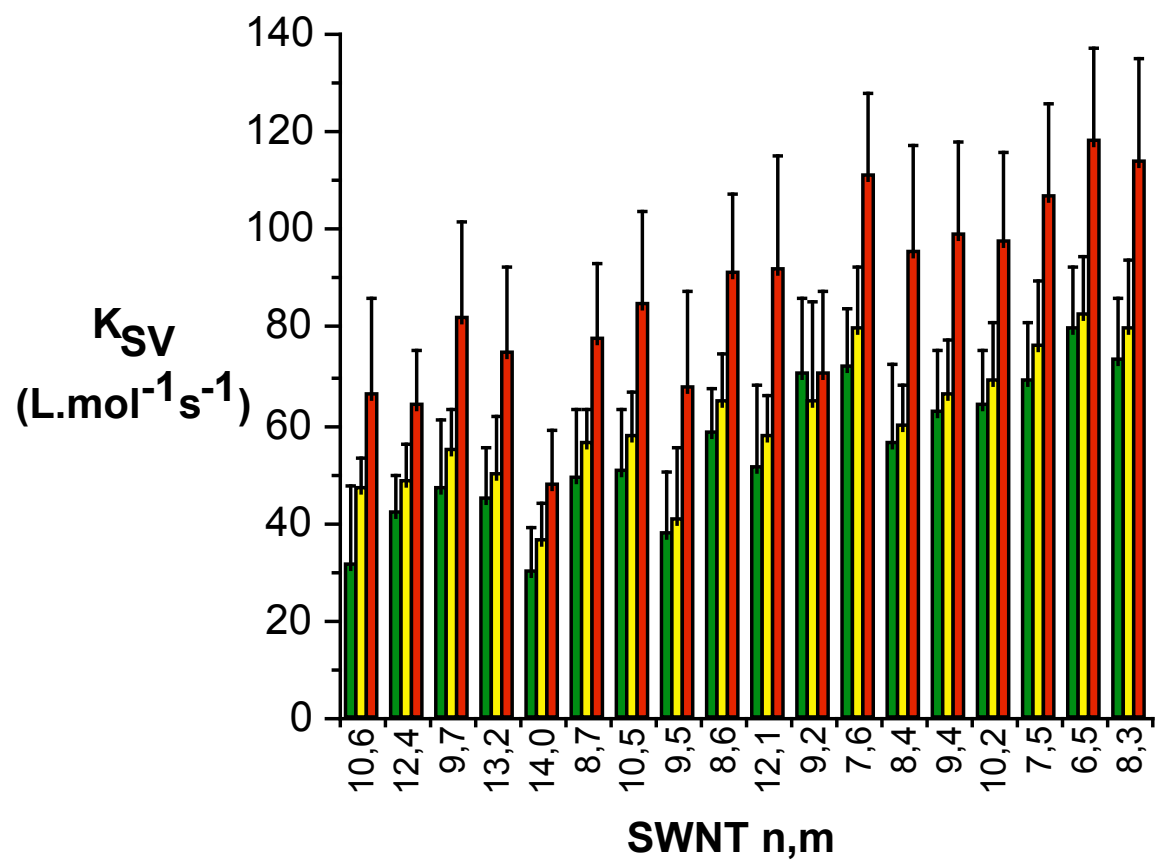

Figure S4. Stern-Volmer quenching constants for SDBS-SWNTs (using $660 \mathrm{~nm}$ excitation as a function) of the $\mathrm{X}^{\mathrm{n}-}$ counter ion $\mathrm{CdX}_{\mathrm{n}} \cdot \mathrm{X}=\mathrm{Cl}^{-}(\square), \mathrm{SO}_{4}{ }^{2-}(\square)$, and $\mathrm{OAc}^{-}(\square)$. 


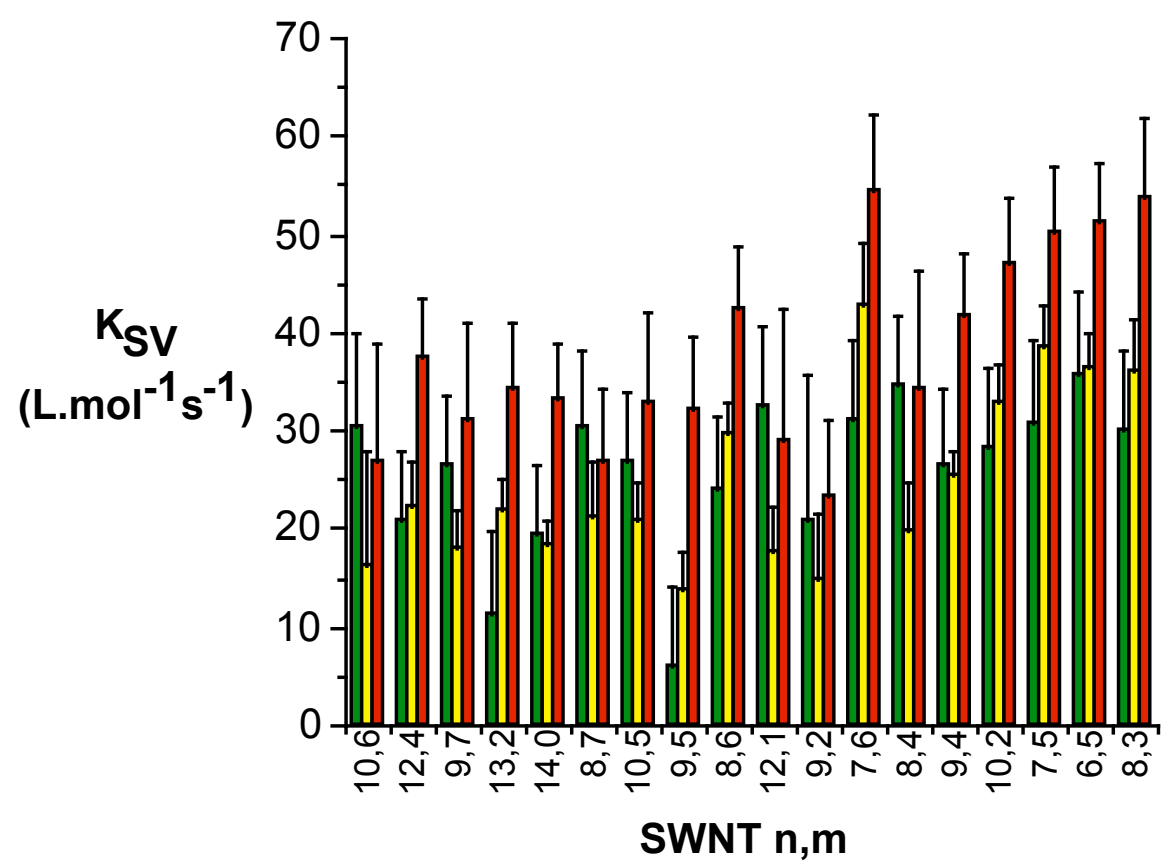

Figure S5. Stern-Volmer quenching constants for SDBS-SWNTs (using $660 \mathrm{~nm}$ excitation as a function) of the $\mathrm{X}^{\mathrm{n}-}$ counter ion $\mathrm{MgX}_{\mathrm{n}} \cdot \mathrm{X}=\mathrm{Cl}^{-}(\square), \mathrm{SO}_{4}{ }^{2-}(\square)$, and $\mathrm{OAc}^{-}(\square)$. 


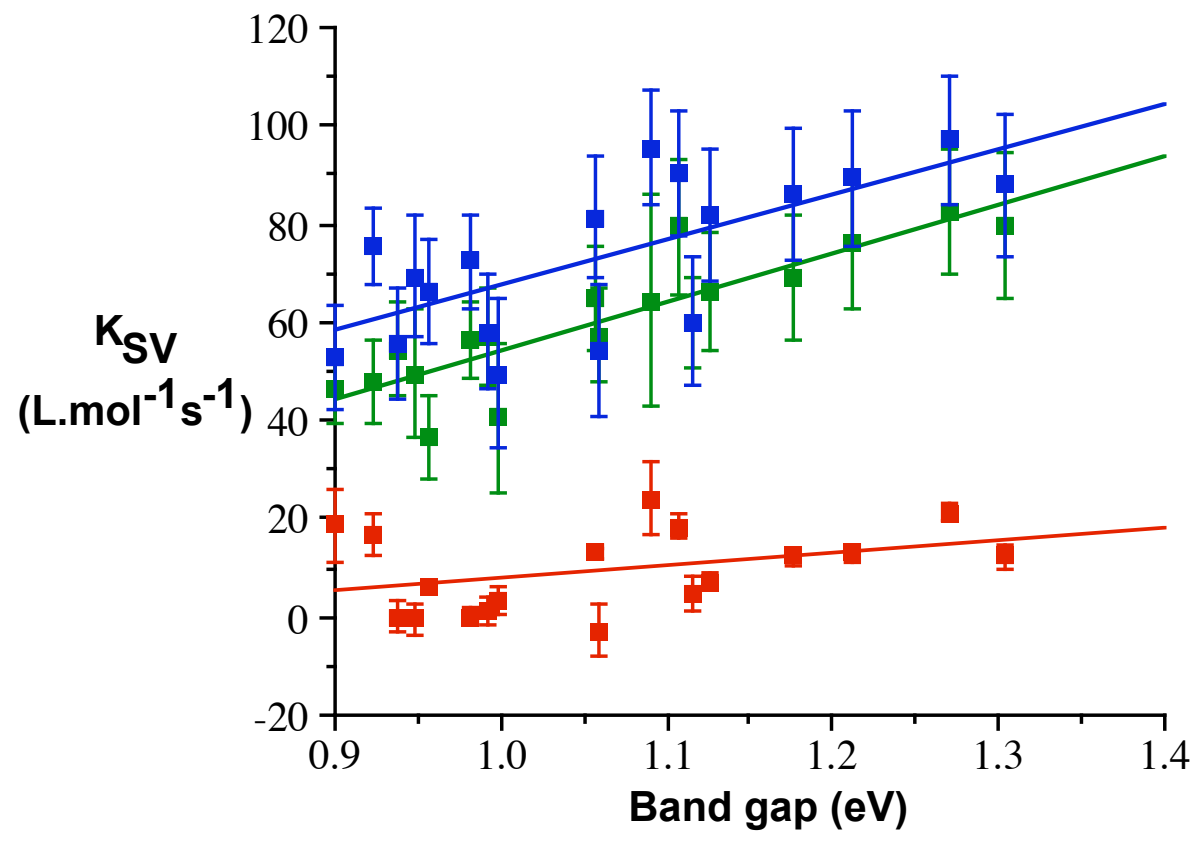

Figure S6. Stern-Volmer quenching constants for SDBS-SWNTs (using $785 \mathrm{~nm}$ excitation as a function) of the SWNT band gap using $\mathrm{M}\left(\mathrm{SO}_{4}\right) . \mathrm{M}=\mathrm{Zn}(\square), \mathrm{Cd}(\square)$, and $\mathrm{Hg}(\square)$. 
(a)

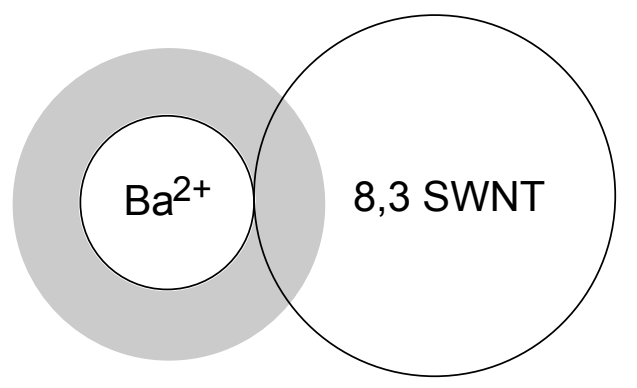

(b)

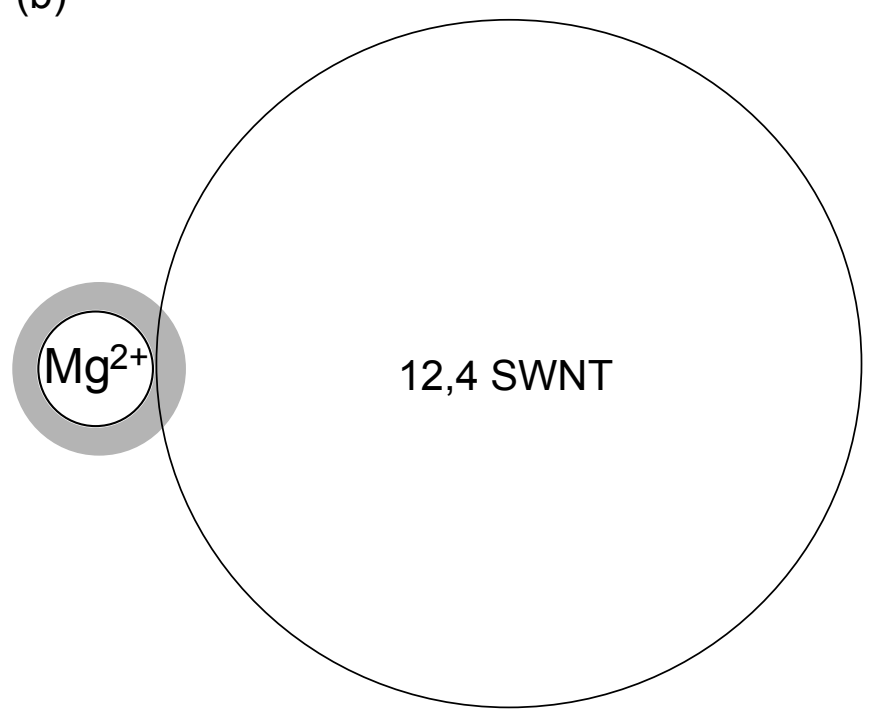

Figure S7. Schematic representation of the extent of influence of the charge on the metal ion on the electronic structure of the SWNT as a function of the relative sizes of ion and SWNT. 